\section{A case of rheumatic fever with acute post-streptococcal glomerulonephritis and nephrotic syndrome caused by a cutaneous infection with beta-hemolytic streptococci}

\author{
Carsten Sauer Mikkelsen, ${ }^{1}$ Allan Gelvan, \\ Ahmad Ibrahim, ${ }^{2}$ Karin Ladefoged ${ }^{1}$ \\ 'Department of Medicine, Queen Ingrid's \\ Hospital, Nuuk, Greenland; \\ 2Department of Nephrology, Copenhagen \\ University Hospital (Rigshospitalet), \\ Denmark
}

\section{Case Report}

A 44-year old woman of Greenlandic origin was referred to Queen Ingrid's Hospital. She was previously healthy apart from excessive alcohol consumption and pulmonary tuberculosis diagnosed two years earlier for which she had received full antimycobacterial treatment. The patient initially complained of a painful traumatic skin lesion of the right lower extremity with a diameter of approximately 2 $\mathrm{cm}$. A few days later, her temperature rose to $39.5^{\circ} \mathrm{C}$ and bullous erysipelas of the area of initial trauma was noted. Laboratory tests revealed a markedly elevated sedimentation rate of $111 \mathrm{~mm} / \mathrm{L}$ hour [2-21], an elevated C reactive protein of $144 \mathrm{mg} / \mathrm{L}[<10]$, leukocytosis $18 \times 10^{9} / \mathrm{L}$ [4.4-11] with neutrophilia and $\times 10^{9} / \mathrm{L}$ [150-450]. Intravenous dicloxacillin and phenoxymethylpenicillin were administered. Culture from the lesion of the right lower extremity was positive for group $A \beta$ hemolytic streptococci (GABHS). In spite of relevant antibiotic treatment, the clinical condition rapidly deteriorated with involvement of the deeper layers of the skin and subcutaneous tissue, spreading across the fascial planes of the subcutis (Figure 1). Necrotizing fasciitis (NF) was diagnosed. Based on positive skin cultures, this condition was considered to be due to GABHS. The patient had no other predisposing factors to NF, specifically no diabetes mellitus, no intravenous abuse and no daily intake of non-steroidal anti-inflammatory drugs (NSAID). Radiological examination of the right lower extremity and foot showed no signs of osseous involvement. Extensive surgical revision of the NF-lesion was performed and meropenem, ciprofloxacin and clindamycin were administered. Approximately three weeks after the initial presentation, impairment of renal function with azotemia and severe nephrotic syndrome with periorbital and peripheral edema were noted.
Laboratory tests showed an elevated creatinine of $386 \mathrm{umol} / \mathrm{L}$ [44-115], BUN: $23.6 \mathrm{mmol} / \mathrm{L}$ [2.56.7], normochromic, normocytic anemia with hemoglobin: $4.9 \mathrm{mmol} / \mathrm{L}$ [7.5-9.0], as well as macroscopic hematuria, renal-creatinine clearance: $30 \mathrm{~mL} / \mathrm{min}$ and U-protein: $5.8 \mathrm{~g} / 24 \mathrm{~h}$ $[<0.15]$. Anti nuclear antibodies (ANA), antineutrophil cytoplasmic antibodies (ANCA), IgA, IgG, IgM and protein electrophoresis were all normal. Blood pressure was increased to $165 / 100$. The hypertension was efficiently treated by ACE-inhibitors and beta blockers. The patient was transferred to Rigshospitalet, Copenhagen where a renal biopsy was performed. The biopsy demonstrated endocapillary glomerulonephritis with proliferation of endothelial cells and infiltration of polymorphonuclear cells. Using immunofluorescence techniques, granular deposits of IgG and C3 were identified as typically seen in acute post-streptococcal glomerulonephritis (APSGN) (Figure 2). During the same period, the patient complained of chest pain. Electrocardiogram (ECG) showed sinus rhythm with no signs of ischemia and no elevation of cardiac troponin I was found. Echocardiography showed moderate reduced left ventricular ejection fraction (LVEF): 35\% [50-65\%] and moderate mitral regurgitation (grade II). Pulmonary pressure was significantly increased $>60 \mathrm{~mm} \mathrm{Hg}$ [1825]. Brain natriuretic peptide (BNP) was sig-
Correspondence: Carsten Sauer Mikkelsen, Department of Dermatology, Stavanger University Hospital, Arnauer Hansensvej 20, Postbox 8100 Postterminalen, 4068 Stavanger Norway. E-mail: c.s.mikkelsen@privat.dk and c.s.mikkelsen@hotmail.com

Key words: rheumatic fever, acute post-streptococcal glomerulonephritis, nephrotic syndrome.

Received for publication: 18 November 2009. Accepted for publication: 14 December 2009.

This work is licensed under a Creative Commons Attribution 3.0 License (by-nc 3.0).

CC Copyright C.S. Mikkelsen et al., 2009 Licensee PAGEPress, Italy

Dermatology Reports 2009; 1:e4

doi:10.4081/dr.2009.e4

nificantly increased $>8000 \mathrm{pg} / \mathrm{mL}[<100]$. There were complaints of arthralgia of the left elbow. There were no other signs of acute rheumatic fever (ARF) and no signs of pharyngitis in the whole period. Chest $\mathrm{X}$ ray and HR-CT of the thorax showed changes in both lungs consistent with old tuberculosis. Two weeks after the first analysis, renal function had improved and $\mathrm{U}$ protein had decreased to $2.6 \mathrm{~g} / 24 \mathrm{~h}$, creatinine $139 \mathrm{umol} / \mathrm{L}$, BUN $9.5 \mathrm{mmol} / \mathrm{L}$. Ultrasound of the kidneys was normal. Echocardiography still

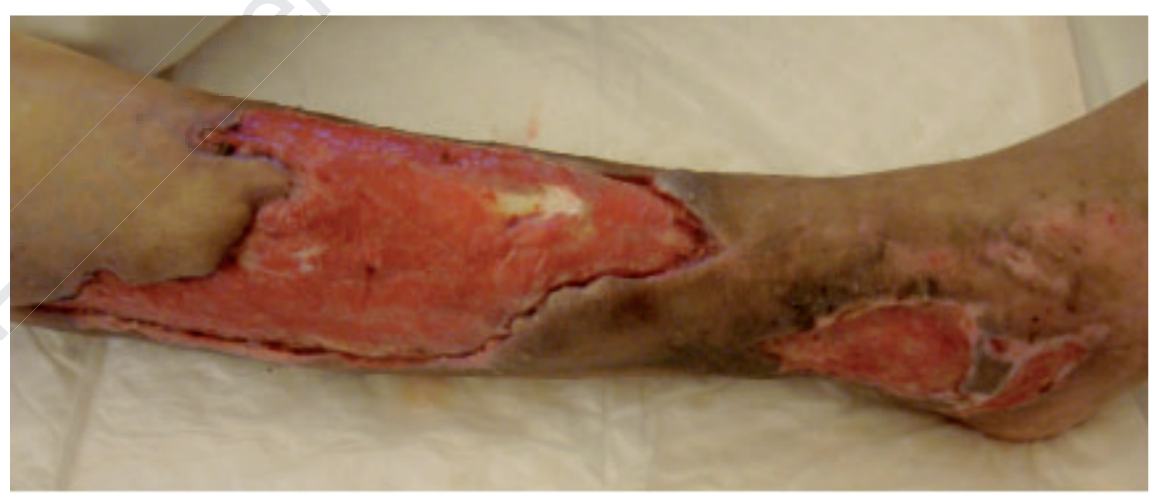

Figure 1. Group A $\beta$-hemolytic streptococci with involvement of the deeper layers of the skin and subcutaneous tissue, spreading across the fascial planes of the subcutis.

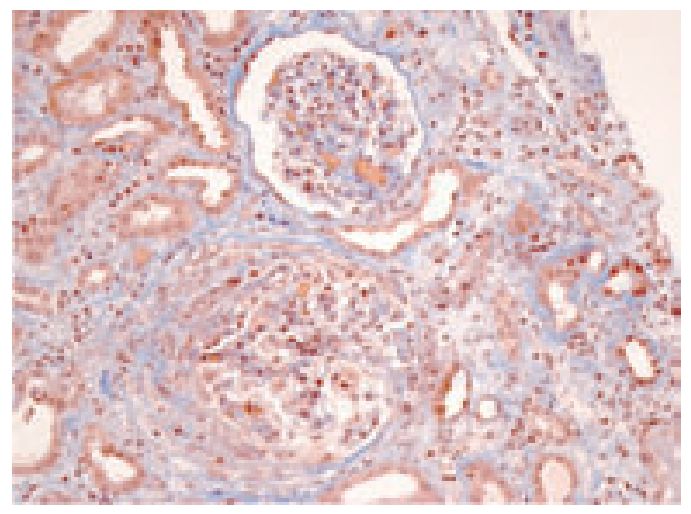

Figure 2. Diffuse proliferative glomerulonephritis with approximately $40 \%$ halfmoons. Significant tubulus atrophy and interstitial fibrosis with inflammation. Endocapillary glomerulonephritis, with accumulation of endothelial cells and inflammatory cells in the capillary lumina. Changes compatible with acute poststreptococcal glomerulonephritis. No signs of systemic disease or vasculitis. 
showed moderate reduced left ventricular ejection fraction (LVEF): $35 \%$ with mild mitral regurgitation (grade I). Continued follow-up of renal and cardiac function is planned.

\section{Discussion}

This case illustrates the simultaneous development of carditis, arthralgia and endocapillary glomerulonephritis with severe nephrotic syndrome preceded by a cutaneous GABHS in the lower right leg. The patient fulfils the revised and updated Jones criteria for classification of ARF based on fever, arthralgia, carditis, increased acute phase reactants (CRP, ESR) and a positive culture of GABHS. ARF develops after group A streptococcal pharyngitis ${ }^{1,2}$ and is only seldom described after GABHS skin infections. ${ }^{3.5}$ Our patient had no signs of pharyngitis but developed NF presumably from a traumatic skin lesion. Culture from the initial lesion of the right lower extremity was positive for GABHS.We propose that our patient developed ARF from her skin infection. We are aware of no history of sore throat described in the literature in cases of ARF. ${ }^{6}$ Also throat swab will be positive in only a third of patients infected with group A streptococcus before antibiotic treatment and in only a tenth of patients afterwards. ${ }^{7}$ GAS pyoderma rather than pharyngitis as a driving force behind ARF has been described in aboriginal communities in Northern Australia. ${ }^{8,9}$ Repeated exposure to GABHS can play a central role in the development of $\mathrm{ARF}^{10}$ as a sort of immune priming. ${ }^{8}$ In our case there was no previous history of pharyngitis or other focus of GABHS infections. ARF and APSGN, two important sequelae of streptococcal throat or skin infections, according to current concepts may be elicited by autoimmune mechanisms due to molecular mimicry between GABHS and human tissue. ${ }^{11}$ APSGN follows infection with a limited number of GABHS serotypes. Type 12 is the most frequent M serotype causing APSGN after pharyn- gitis or tonsillitis, whereas M-49 is the type most frequently related to pyoderma-associated nephritis. ${ }^{12}$ The patient had no earlier symptoms of heart disease and so we strongly suspect the high BNP and and moderate mitral regurgitation to be carditis related to ARF. In affluent societies where GABHS disease is uncommon apart from pharyngitis in childhood, increasing numbers of NF and streptococcal toxic shock syndrome (STSS) have been seen, as well as an upsurge of acute rheumatic fever apparently restricted to parts of the United States. ${ }^{13-16}$ In some of these locations, a virulent M1 serotype GABHS clone has been found. ${ }^{17}$ We suggest a possible relation between a virulent GABHS clone causing NF and ARF.

\section{References}

1. Wannamaker L. The chain that links the heart to the throat. Circulation 1973;48:918.

2. Wannamaker L. Differences between streptococcal infections of the throat and of the skin. N Engl J Med 1970;282:78-85

3. Popat K. Riding W. Acute rheumatic fever following streptococcal wound infection. Postgrad Med J 1976;52:165-70.

4. McDonald MI, Towers RJ, Andrews R, et al. The dynamic nature of group A streptococcal epidemiology in tropical communities with high rates of rheumatic heart disease. Epidemiol Infect 2008;136:529-39.

5. McDonald MI, Towers RJ, Andrews R, et al. Molecular typing of Streptococcus pyogenes from remote Aboriginal communities where rheumatic fever is common and pyoderma is the predominant streptococcal infection. Epidemiol Infect 2007; 135:1398-405.

6. Wilson NJ, Neutze JM. Echocardiographic diagnosis of subclinical carditis in acute rheumatic fever. Int J Cardiol 1995;50:1-6

7. Jansen TLThA, Janssen M, Van Reil PLCM.
Acute rheumatic fever or post-streptococccal reactive arthritis: a clinical problem revisited. Br J Rheumatol 1998;37:335-40.

8. McDonald M, Currie BJ, Carapetis JR. Acute rheumatic fever: a chink in the chain that links the heart to the throat. Lancet Infect Dis 2004:4:240-5.

9. Currie BJ, Carapetis JR. Skin infections and infestations in Aboriginal communities in northern Australia. Australas $\mathrm{J}$ Dermatol 2000;41:139-43.

10. Cunningham MW. Pathogenesis of group A streptococcal infections. Clin Microbiol Rev 2000;13:470-511

11. Burova AL, Nagornev VA, Pigarevsky PV, Gladilina MM, Seliverstova, et al. Myocardial tissue damage in rabbits injected with group A streptococci, types M1 and M22. Role of bacterial immunoglobulin Gbinding surface proteins. APMIS 2005; 113:21-30.

12. Bisno AL, Brito MO, Collins CM. Molecular basis of group A streptococcal virulence. Lancet Infect Dis 2003:3:191-200.

13. Stevens DL. The flesh-eating bacterium: what's next? J Infect Dis 1999;179:S36674.

14. Chelsom J, Halstensen A, Haga T, Højby EA. Necrotising fasciitis due to group A Streptococci in western Norway: incidence and clinical features. Lancet 1994;344: 1111-15.

15. Kaul R, McGeer A, Low DE, Gren K, Schwartz B. Population based surveillance for Group A streptococcal necrotizing fasciitis: Clinical features, prognostic indicators, and microbiologic analysis of seventy cases. Am J Med 1997;103:18-24.

16. Haywood C, McGeer A, Low D. Clinical experience with 20 cases of Group A streptococcus necrotizing fasciitis and myo necrosis: 1995-1997. Plast Reconst. Surg 1999, 103: 1567-73

17. Cleary PP, Kaplan EL, Handley JP, et al. Clonal basis for resurgence of serious Streptococcus pyogenes disease in the 1980`s. Lancet 1992;339:518-21. 